\title{
Investigation of Hot Section (Nozzle Guiding Vane) Distress due to Interaction of Thermal Barrier Coatings with CMAS
}

\author{
QADEER. Ahmed ${ }^{a^{*}}$, IMRAN Nazir Qureshi ${ }^{\mathrm{b}}$, IFIKHAR Us Salam \\ Institute of Industrial Control System, Rawalpindi, Pakistan \\ aqadeerahmad90@gmail.com, bimrannq@yahoo.com
}

Keywords: TBC, CMAS, Turbine, Nozzle Guiding Vanes, Hot Corrosion, SEM

\begin{abstract}
An investigation of distress of hot section nozzle guiding vane (NGV) was carried out. Thermal barrier coatings (TBCs) were applied to the components of gas turbine engines to operate at higher temperatures i.e. up to $1200{ }^{\circ} \mathrm{C}$. The cause of failure was hot corrosion of TBCs by chemical entities from atmosphere like oxides of $\mathrm{Al}, \mathrm{Ca}, \mathrm{Si}$ and $\mathrm{Mg}$ (CMAS). Source of CMAS was dust, which was ingested to airfoil engine components. Different techniques like scanning electron microscope, boroscopy, optical microscopy, X-ray Diffraction and optical emission spectroscopy were utilized to investigate the failure of nozzle guiding vanes.
\end{abstract}

\section{Introduction}

Thermal barrier coatings (TBCs) are generally used in jet engines and land-based turbines as insulating layers to protect the underlying components from the high temperatures. Typical TBCs have a two-layered structure consisting of an oxidation protective bondcoat and thermally insulating yttria stabilized zirconia (YSZ) topcoat. Bondcoat is important for adhesion and grading the thermal expansion mismatch between the top and substrate. A typical bond coat contains $\mathrm{Ni}, \mathrm{Cr}, \mathrm{Al}$, and $\mathrm{Y}$, with $\mathrm{Ni}$ as the primary element for nickel-alloy substrate application [1-6]. A third layer present in a TBC is the thermally grown oxide (TGO). This layer forms during TBC deposition and engine operation [4-5]. Two different coating techniques are being utilized for TBC coating i.e. air plasma spray (APS) and electron beam physical vapor deposition (EB-PVD) [1, 12]. With APS, topcoat exhibited porosity with lamellar structure while EB-PVD has columnar porous structure. YSZ is effective thermal barrier and columnar porous morphology consents it strain tolerance characteristic [5-6].

During service at high temperature TBCs are susceptible to thermochemical and thermomechanical degradation via environment. Dust ingested through air, yield deposits of metallic and non-metallic oxides like $\mathrm{CaO}, \mathrm{MgO}, \mathrm{Al}_{2} \mathrm{O}_{3}, \mathrm{SiO}_{2}(\mathrm{CMAS})$ and $\mathrm{Fe}_{2} \mathrm{O}_{3}$ on engine components $[1,2,5,6]$. At high temperature approaching $1200{ }^{0} \mathrm{C}$ thermochemical attack begins $[2,6]$. Thermochemical degradation refers to chemical reaction between YSZ and foreign deposits. Consequently thermochemical degradation de-stabilizes YSZ by withdrawing yttria out it, also destroys the columnar morphology making it prone to thermomechanical degradation.

Present study is performed on vanes of high pressure turbine (HPT) of aircraft engine. Results are discussed in viewpoint of corresponding CMAS-TBC high temperature interaction.

\section{Experimental Procedure}

Study was performed on vanes recovered from airfoil engine after hot distress of engine HPT section. Visual observation, boroscopy, optical microscopy, XRD, Metallography, radiography and SEM-EDS were employed to investigate the hot distress. Boroscopy is utilized to study the internal condition of the vanes e.g., choking of cooling holes, deposits of foreign material ingested during service etc. After boroscopic inspection, internal surface deposits were collected and studied with SEM-EDS and X-ray diffraction. Jeol XRD model JDX-9C was used for X-ray diffraction pattern of powder deposits collected from internal surface of vanes. Sample was tested within $2 \theta$ range of $20^{\circ}-100^{\circ}$ with step size of $0.05^{\circ}$. Phase analysis was performed to identify the presence of typical calcia-magnesia-alumina-silicates (CMAS). SEM was utilized to examine the distressed surface of vanes and cross section of the vanes. 


\section{Results}

Visual Observation. $2^{\text {nd }}$ stage nozzles guiding vanes (NGV's) were inspected. NGV's were severely damaged from both pressure and suction side. Vanes were coated with YSZ and damage phenomenon like delamination, degradation and foreign material deposition were evident on surface. Cracks due to merging of cooling holes were present on pressure side of the NGV's (Fig. 1).
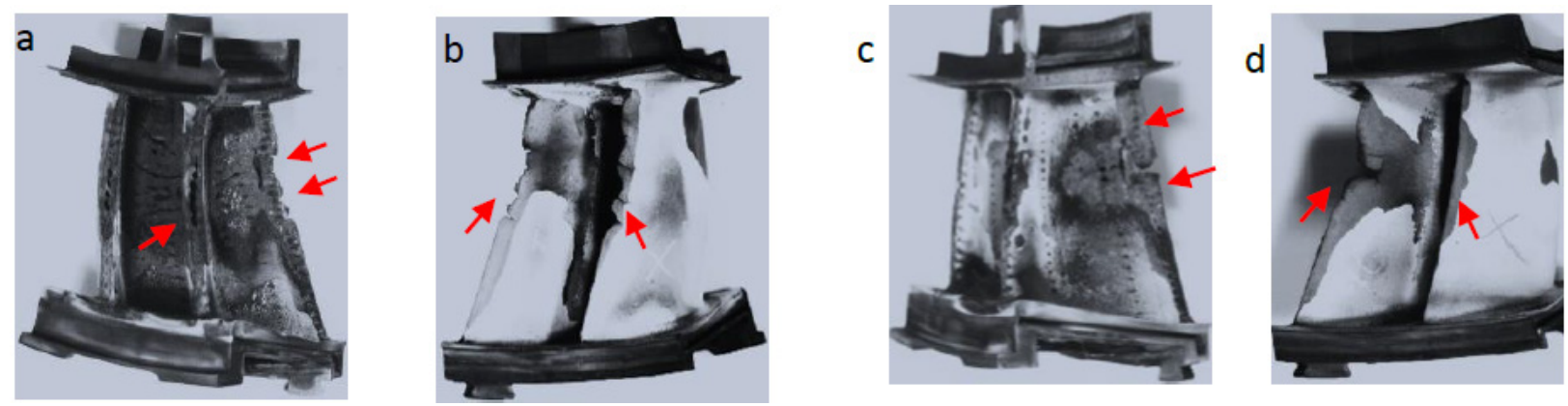

Fig. 1. Photograph of NGVs (a \& c) Pressure side, delamination of coating, erosion, cracks and loss of metal and crack at the leading edge ( $b$ \& d) suction side, showing coating delamination of pressure side.

Boroscopy. Internal surface inspection through boroscopy showed evidences of foreign deposits. Deposits were present all around the internal surface (Fig. 2). These were introduced usually, either with low quality fuel or ingested air from atmosphere.
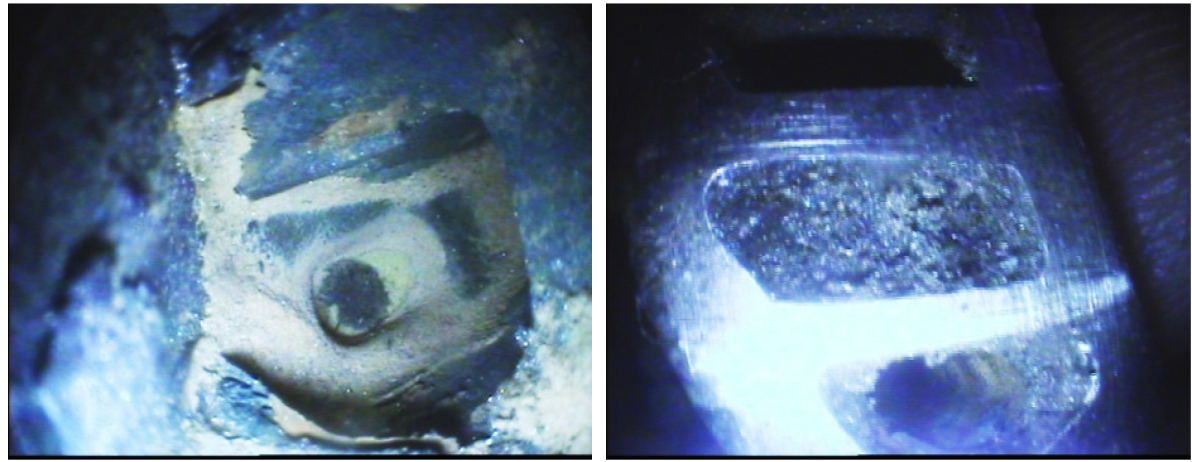

Fig. 2. Photographs of NGVs, (a) foreign deposits on internal surface,

(b) Blockage of internal cooling path with foreign material.

X-ray Radiography. Radiograph of NGV's was taken to reveal the any hidden cracks underneath coating. Radiography revealed cracks on pressure side and thinning of substrate material. This indicated prolonged time high temperature exposure (Fig. 3)

X-ray Diffraction. Foreign deposits were extracted from internal surface and XRD analysis was performed. Analysis reported that deposits consist of four different constituents, calcium oxide, magnesium oxide, aluminum oxide and silicon oxide $\left(\mathrm{CaO}-\mathrm{MgO}-\mathrm{Al}_{2} \mathrm{O}_{3}-\mathrm{SiO}_{2}\right)$. Combination of oxides of $\mathrm{Ca}, \mathrm{Mg}, \mathrm{Al}$ and silicon is collectively known as CMAS [3]. These are fundamental constituents of the dust (Fig. 4). 


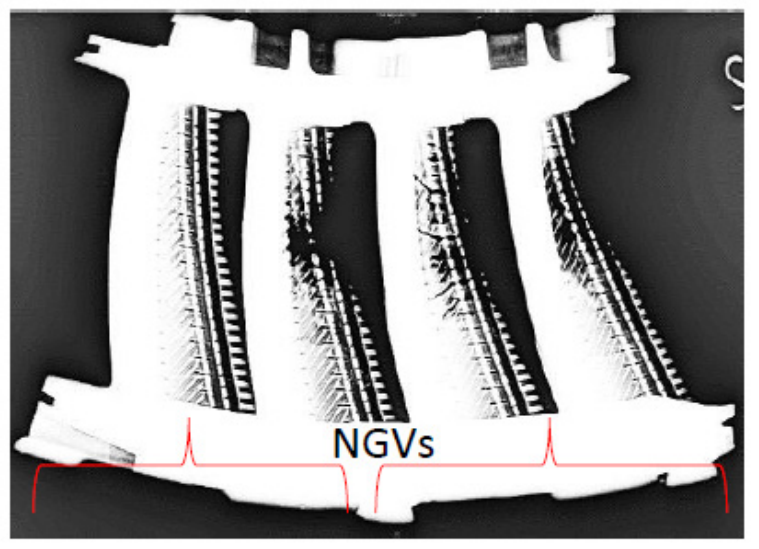

Fig. 3. Radiograph of turbine nozzle guide vanes internal structure.

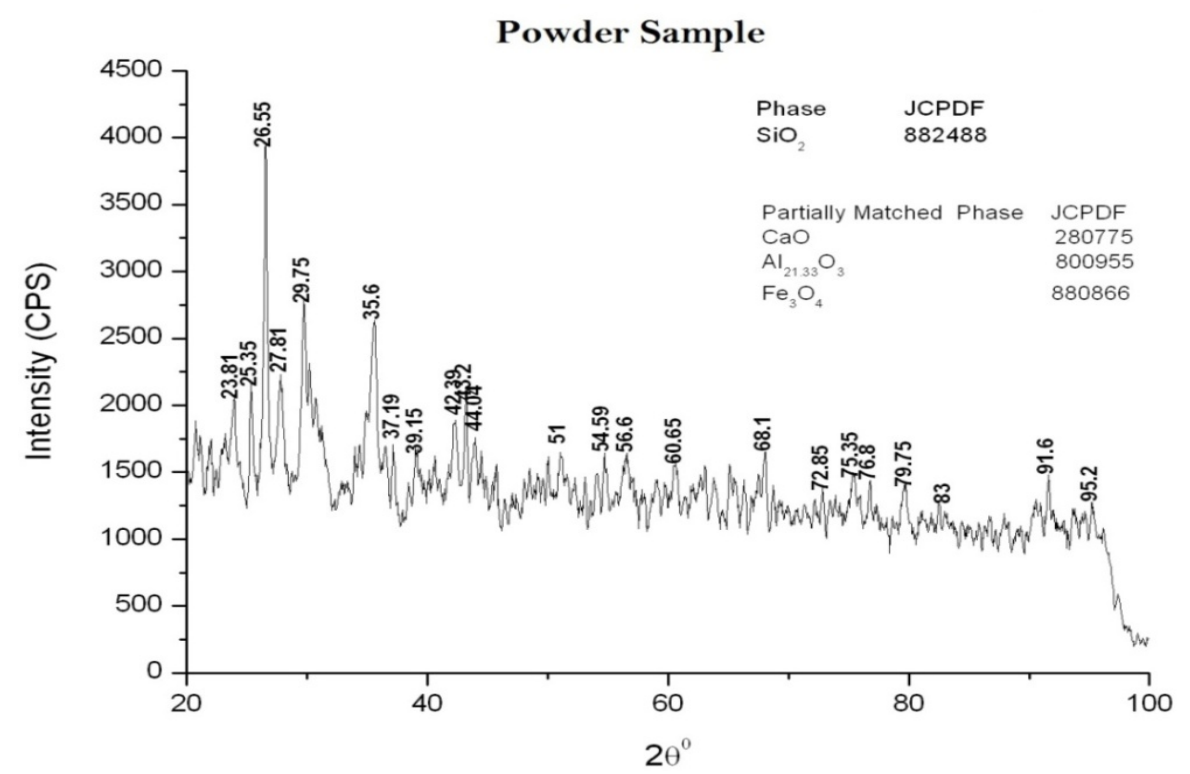

Fig. 4. XRD Spectrums of CMAS Powder, showing existence of $\mathrm{SiO}_{2}$ phase and partial existence of $\mathrm{CaO}, \mathrm{Al}_{2} \mathrm{O}_{3}$ and $\mathrm{Fe}_{2} \mathrm{O}_{3}$.

Optical Microscopy. EDS analysis confirmed substrate material as PWA 1484/1487, see Table 1 Metallographic Samples were prepared using conventional techniques grinding, polishing and etching respectively. Super alloys etchant $200 \mathrm{~g} \mathrm{FeCl}_{3}, 200 \mathrm{~mL} \mathrm{HCl}$, to $1000 \mathrm{~mL}$ for $90 \mathrm{~min} 212^{\circ} \mathrm{F}$ is used to reveal the microstructure. Typical super alloy structure consisting of $\gamma$ and $\gamma$ ' was observed. (Fig. 5)
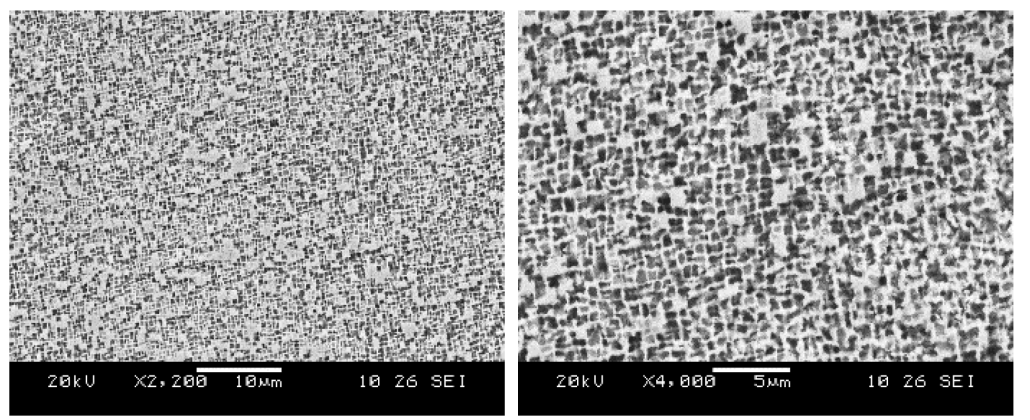

Fig. 5. Micrographs of NGV's base material typical super-alloy structure having gamma prime $\left(\gamma^{\prime}\right)$ in gamma $(\gamma)$ matrix. 
Table 1. Presenting composition of PWA 1484/1487(wt. \%).

\begin{tabular}{|l|l|l|l|l|l|l|l|l|l|}
\hline Elements & Ni & Cr & Mo & W & Re & Ta & Al & Co & Hf \\
\hline PWA1484 & Bal. & 5 & 2 & 6 & 3 & 8.7 & 5.6 & 10 & 0.1 \\
\hline PWA1487 & Bal. & 5 & 2 & 6 & 3 & 8.7 & 5.6 & 10 & 0.25 \\
\hline
\end{tabular}

SEM-EDS. Characteristic columnar morphology of electron beam physical vapor coating was observed under SEM. EDS analysis reported that coating is yttria stabilized zirconia (YSZ) known as thermal barrier coating TBC. Surface assessment under SEM-EDS revealed that CMAS (CaO$\mathrm{MgO}-\mathrm{Al}_{2} \mathrm{O}_{3}-\mathrm{SiO}_{2}$ ) was present on entire surface of the NGVs. Moreover oxide of iron was also observed at often points. CMAS was infiltrated through the columnar structure of PVD coating. At many sites PVD coating was absent due to interaction of CMAS and yttria stabilized zirconia at high temperature (hot corrosion). Electron microscopy revealed delamination of TBC coating and burn through of substrate material caused by high temperature exposure. Cracks formation owing to merging of cooling holes was also apprehended. (Fig. 6)
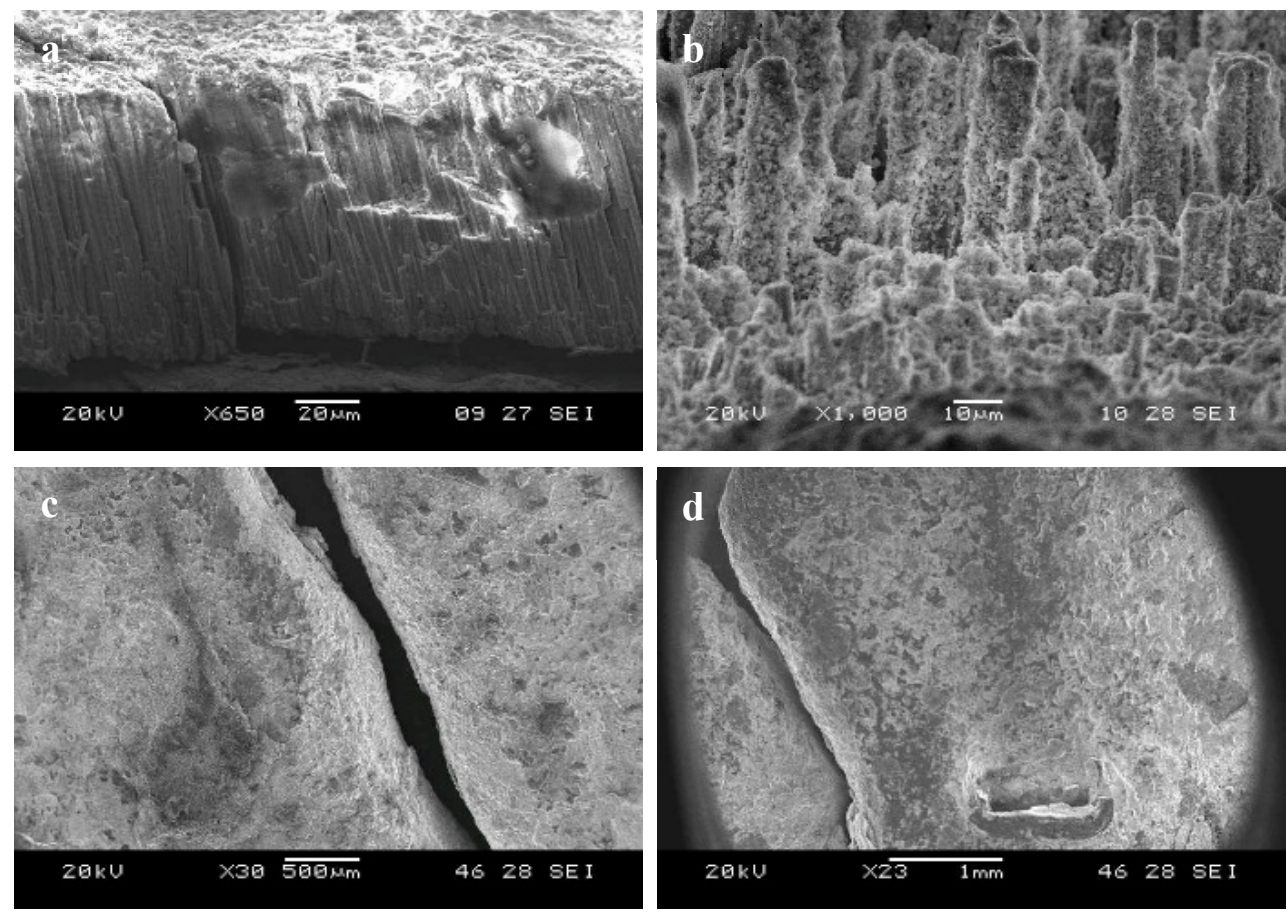

Fig. 6. Micrographs of NGVs surface expressing (a) columnar TBC, crack in TBC, (b) infiltration of CMAS in EB-PVD TBC, (c) crack formed due to merging of cooling holes, (d) choking of cooling hole.

\section{Discussion}

$2^{\text {nd }}$ generation Nickel base super alloys (1484/1487) are base material of the NGVs. Under study Super Alloys are being used for high temperature turbine components since long. Momentous increase in high temperature strength capability has been achieved in a second-generation nickelbase single crystal alloy designed for advanced military and commercial turbine airfoil application [7].

The EDS analysis of the blade sample revealed that the coating used in the blades was YSZ, Thermal Barrier Coating (TBC).These type of coatings have become essential part in turbine engines, over the past decades [1]. TBC systems enhance system ability to work at elevated temperatures. TBCs work as insulator in between component base and high temperature 
environment. Thermal barrier coating deposited by EB-PVD containing columnar structure has capability of strain tolerance due to volumetric changes at high temperature. At high temperatures the substrate material expands and so do the columns of TBC. In this way columnar TBC compensate volumetric change and reduces thermo-mechanical stresses in coating. On cooling the reverse process occurs $[5,6]$. This ability of TBC (EB-PVD) coating enhances system's life. TBCs are subject to many kinds of degradations such as erosion; foreign object damage (F.O.D), oxidation etc. [1]. Which deteriorates integrity and mechanical properties of the whole system.

In order to improve engine performance, increase in the turbine inlet temperature has taken place. Increase in turbine inlet temperature highlighted a new type of damage i.e., corrosion by molten Calcium-Magnesium-Alumina Silicates known as CMAS [1].

Deposits of foreign material (CMAS) were identified on NGVs. Analysis found that CMAS infiltrated the TBC columnar structure Such infiltration at high temperature is called hot corrosion by molten CMAS $[6,12]$. The infiltration of CMAS was either due to dirty fuel or dust ingested through the air intake (Fig.2). The origin of this failure was high temperature interaction of YSZ (TBC) with molten (CMAS) deposits. This caused allotropic change in TBC. Allotropic change began with depletion of yttria in YSZ, which converted the tetragonal stable structure into monoclinic structure which was not stable to service temperature $[1,6]$. Consequently destabilization of the YSZ occurred. XRD analysis confirmed the presence of iron oxide at the surface (Fig. 4); $\mathrm{Fe}_{2} \mathrm{O}_{3}$ worked as flux and decreased the melting temperature of CMAS [6]. After melting CMAS infiltrated into the TBC. Upon cooling infiltrated CMAS solidified. Solidified CMAS in between columns destroyed its capability to withstand volumetric changes [6]. Which extinct the TBC strain tolerance. Reduction in strain tolerance of TBC reduced its capacity to withstand thermo-mechanical stresses. Delamination and cracks were subsequent results of these thermo-mechanical stresses (Fig.6 a, b) [8-11].

Chemical interaction between yttria stabilized zirconia top coating (YSZ) and CMAS at high temperature generated new phase. Formation of new phase introverted yttria from TB (YSZ) Coating which subsequently destabilized the TB Coating [6].

Evidence of higher temperature exposure of substrate material was observed during investigation (Fig. 6c, d). This may be due to delamination of thermal barrier coating because of hot corrosion and CMAS deposition at internal surface of engine components. CMAS deposits (internal surface) worked as an insulator and decrease heat conduction from blade surface to cooling air. Both delamination of Thermal barrier coating from external surface and decrease in heat conduction from internal surface raised the temperature of component up to distressing level.

\section{Summary}

Hot corrosion due to CMAS is the main cause of distress of components leading to delamination of thermal barrier coating and burn through of base metal. Preexisting defects in coating, CMAS deposition on internal surface and blockage of cooling holes, strengthen the aforementioned damage.

\section{References}

[1] G. Pujol, F. Ansart, J.-Pierre Bonino, A. Malié, S. Hamadi, Sur. Coat. Tech., 237 (2013) 71-78.

[2] G. Witz a, V. Shklover, W. Steurer , S. Bachegowda , H.-P. Bossmann, Sur. Coat. Tech., 265 (2015) 244-249.

[3] A. R. Krause, H. F. Garces, B. S. Senturk, and N. P. Padture, Ceram. Soc., 97 (2014) 39503957.

[4] L. He-Fei, G. Hong-bo, GONG Sheng-kai, Trans. Nonferrous Met. Soc. China 17 (2007) 811815.

[5] C. Mercer, S. Faulhaber, A.G. Evans , R. Darolia, Acta Materialia 53 (2005) 1029-1039. 
[6] M.H. Vidal-Setif, N. Chellah, C. Rio, C. Sanchez, O. Lavigne, Sur. Coat. Tech., 208 (2012) 3945.

[7] A. D. Cetel and D. N. Duhl, Materials Engineering Pratt \& Whitney Street East Hartford, CT 06108

[8] M.P. Borom, C.A. Johnson, L.A. Peluso, Sur. Coat. Tech., 86-87 (1996) 116-26.

[9] J. Kim, M.G. Dunn, A.J. Baran, D.P. Wade, E.L. Tremba, Gas Turbines Power, Trans. J. Eng., 115 (1993) 641-751.

[10] F.H. Stott, D.J. de Wet, R. Taylor. In: Froes et al., editors. Manchester: SAMPE, 3 (1992) 92101.

[11] J.L. Smialek, F.A. Archer, R.G. Garlick. In: Froes et al., editors. Cleveland, OH: SAMPE, 3 (1992) M63-77.

[12] J. Song, Xi. Zhang, C. Deng, C. Deng, M. Liu, K. Zhou, X. Tong, Cer. Inter., 42 (2016) 1633169. 